\title{
Predictors of pediatric tuberculosis in public health facilities of Bale zone, Oromia region, Ethiopia: a case control study
}

\author{
Bereket Gebremichael ${ }^{1,5^{*}}$, Tsega-Ab Abebaw ${ }^{2,5}$, Tsedey Moges ${ }^{3,5}$, Admas Abera Abaerei, ${ }^{4,6}$
} and Nadia Worede ${ }^{1,5}$

\begin{abstract}
Background: Tuberculosis is among the top ten cause of death (9th) from a single infectious agent worldwide. It even ranks above HIV/AIDS. It is among the top 10 causes of death among children. Globally there are estimates of one million cases of TB in children, 76\% occur in 22 high-burden countries among which Ethiopia ranked 8th. Despite this fact, children with TB are given low priority in most national health programs. Moreover reports on childhood TB and its predictors are very limited. Therefore this study aimed to assess predictors of pediatric Tuberculosis in Public Health Facilities.

Methods: Unmatched case control study among a total samples of 432 (144 cases and 288 controls) were done from August to December 2016 in Bale zone, South East Ethiopia. Pediatric TB patients who attended health facilities for DOTS and those who attended health facilities providing DOTS service for any health problem except for TB were the study population for cases and controls, respectively. For each case two consecutive controls were sampled systematically. Data were collected using pretested and structured questionnaire through face to face interview with parents. Binary and multivariable logistic regression analyses were employed to identify predictors of Tuberculosis.

Result: Among cases there were equal number of male and female 71(50\%). However among control 136 (47.9\%) were male and the rest were female. The mean (standard deviation) of age among cases was $8.4( \pm 4.3)$ and controls were $7.3( \pm 4.1)$. The odds of TB were 2 times (AOR, 95\% Cl =1.94(1.02-3.77)) more likely among 11-15 age group children when compared with children of age group $\leq 5$. HIV status of the child, children who were fed raw milk and absence of BCG vaccination were the other predictors of pediatric TB with AOR 13.6(3.45-53.69), 4.23(2.26-7.88), and 5. 46(1.82-16.32) respectively.
\end{abstract}

Conclusion: Children who were not BCG Vaccinated were at risk of developing TB. Furthermore, HIV status, age of the child and family practice of feeding children raw milk are the independent predicators of pediatric TB in the study area.

Keywords: Tuberculosis, Pediatrics, Predictors of pediatric TB, Bale zone

\section{Background}

Tuberculosis (TB) is a chronic infectious disease caused by Mycobacterium tuberculosis (MTB). It typically affects the lungs (pulmonary TB) but can affect other parts of the body as well (extra pulmonary TB) [1]. If properly treated it is medicable in virtually all cases but it remains

\footnotetext{
* Correspondence: bdpapi3@gmail.com

${ }^{1}$ College of Medicine and Health Sciences, Allied School of Health Science,

Addis Ababa University, Addis Ababa, Ethiopia

${ }^{5}$ Addis Ababa, Ethiopia

Full list of author information is available at the end of the article
}

as one of the major public health problems worldwide. It is a major cause of disease and death worldwide and has infected around one-third of the world population [2]. In 2015, there were an estimated 10.4 million new (incident) TB cases worldwide among which 1.0 million (10\%) were children. People living with HIV accounted for 1.2 million (11\%) of all new TB cases. WHO South-East Asia and African region contributed for higher number (greater than 70\%) of incident cases [3, 4].

Even though the proportion of TB in children is smaller, the urgency of the problem of $\mathrm{TB}$ in children cannot be

(c) The Author(s). 2018 Open Access This article is distributed under the terms of the Creative Commons Attribution 4.0 International License (http://creativecommons.org/licenses/by/4.0/), which permits unrestricted use, distribution, and reproduction in any medium, provided you give appropriate credit to the original author(s) and the source, provide a link to the Creative Commons license, and indicate if changes were made. The Creative Commons Public Domain Dedication waiver (http://creativecommons.org/publicdomain/zero/1.0/) applies to the data made available in this article, unless otherwise stated. 
underestimated. They are at high risk of developing TB due to their developing immune system. The majority of them tends to develop severe and disseminated form of TB within a year or two and could die even before their diagnosis [5]. Every day around 200 children die due to tuberculosis: disease that can be prevented and treated [6]. According to the $2015 \mathrm{WHO}$ estimate and study on the global burden of tuberculosis mortality in children, the annual burden of childhood mortality were over 200,000 worldwide $[7,8]$. Given the challenge in diagnosing childhood TB, the actual burden of TB in children is likely higher than the estimate $[6,9]$.

In the last 10 years tuberculosis has reemerged as a major worldwide public health hazard with increasing incidence among adults and children. Even though cases among children are not as prevalent as adult, infected children are a reservoir from which many adult cases will arise [4]. Ethiopia is among the 22 high burden countries ranked eighth in the world with an estimated TB incidence (all forms) of 378 new cases per 100,000 persons. It is not surprising if the country is also among high burden countries with childhood TB. Children are at high risk of developing TB due to their un matured immune system. In Ethiopia, close to $13 \%$ of notified TB cases were children [10].

TB is one of the top ten diseases that cause childhood morbidity and mortality in Oromia regional state and specifically in Bale Zone. In 2014/15 G.C around 3345 population were on DOTS among which pediatric cases were around 628 which account around 18.77\% [11].

According to studies done in different areas, different factors that are directly and indirectly related to poverty like malnutrition, living standard and style, some demographic characteristics are assumed to be independent predictors of childhood tuberculosis [12, 13-16]. Even though there are studies that focus on childhood TB done in Ethiopia, they only focus on prevalence and treatment outcome and most of the studies were cross sectional in their design $[10,17,18,19]$. Very few studies were done on risk factors of TB but they were done on the general population or focus on the adult population even though the case of pediatric TB should be considered alone $[15,16,19]$. Moreover children are the most vulnerable group for any health related problem. In addition there is very limited study done in Ethiopia, particularly in this study area on factors associated with the development of TB among children. Therefore this study was aimed to asses' predictors of tuberculosis among children in public health facilities of Bale Zone, south east Ethiopia.

\section{Methods}

\section{Study area and period}

The study was conducted in public health institutions of Bale Zone, from January to June 2016.
Bale zone is one of the zones in Oromia Regional State and it comprises of 21 districts. Robe is an administrative town which is $423 \mathrm{~km}$ away from Addis Ababa, the capital city of Ethiopia. According to the 2013 population estimation, the total population of the zone was around 1,661,818 among this 791,024 (47.6\%) were children below 15 years of age. In bale zone there are around 84 health centers and four hospitals that are providing DOTS both for adult and children [11].

\section{Study design}

Institution based unmatched case control study was conducted among cases or children with TB and controls or children without TB in selected public health facilities of Bale Zone, south east Ethiopia.

\section{Population \\ Source and study population}

All patients $\leq 15$ years of age who came to public health facilities in Bale Zone were the source population and the study population wereall patients $\leq 15$ years of age who came to the selected Public health Facilities.

\section{Cases}

All children $\leq 15$ years of age who were on anti TB treatment. TB diagnosis was made based on the national comprehensive Tuberculosis, Leprosy, TB/HIV diagnosis and treatment manual [20]. The standard is applicable in every part of the country. Children who had TB but were attending OPD for health problems other than $\mathrm{TB}$ were excluded because one subject might have been selected twice since TB treatment is given in separate TB clinic.

\section{Controls}

All children $\leq 15$ years of age who were on outpatient department and who were not diagnosed for TB.

\section{Exclusion criteria}

Respondents who were critically ill during the data collection, those who come without parents were excluded because they were assumed unable to respond to the questions accordingly. Children who had the following symptoms during the immediate weeks before data collection, cough for more than 2 weeks duration, weight loss, night sweating and cervical \& inguinal lymph node swelling were also excluded from cases and controls.. Those with the above symptom were excluded because we assume that diseases that have relatively the same symptoms with TB might be included in the case and might affect the study findings. 


\section{Sample size and sampling procedure Sample size determination}

Sample size was calculated using Epi info version 3.5.1 software by employing proportion difference approach. Proportion difference approach is used because we assume that there is an exposure difference on risk factor among cases and controls. To detect whether the assumed difference exists between the two the following assumption were used. Since there were no study found in the study area and similar population: 1 to 2 cases to controls ratio was recruited to achieve $80 \%$ power and detect an odds ratio of 2.0 at $5 \%$ significance level if $20 \%$ or more of the general population was exposed to the risk factors at $95 \%$ confidence level. Then Total Estimated sample size was 411, (137 cases and 274 controls). Adding a 5\% nonresponse rate, a total of 144 cases and 288 controls were the enrolment target.

\section{Sampling procedures}

As it is described in the study area section, there are 4 hospitals and 84 health centers that are providing DOTS service in Bale Zone. The 4 hospitals were purposively selected. In addition around 1/5th of the health centers (16 health centers) were randomly selected by first stratifying all the districts in to three agro ecological classification; Highland, Mid land and Low land. From Highland, Midland and Low land agro ecologic strata 5, 5 and 6 health centers were randomly selected respectively. Health centers were proportionally allocated to the number of health center in each agro ecologic strata.

To decrease the exposure disease relationship that can be due to the duration or prognosis of the disease, TB patients on intensive phase (patient on the first 8 weeks of treatment when the treatment is given under direct supervision of health care worker) were selected. For each case two consecutive controls that fulfill the inclusion criteria were sampled systematically from OPD of the same health facilities from which cases were drawn. Controls were selected by using systematic random sampling method. In order to determine the interval to select controls for each case, the 3 days average patient flow was fixed. The interval was calculated for every health facilities specifically.

\section{Data collection tools and procedures}

Data were collected on the socio demographic, environmental, health related characteristics of the study participants. Semi structured questionnaires were used to collect the data. Most of the questions were adapted and modified from previous study and reviewing of different literatures $[12,21,13-15,22]$. The questionnaires were first developed in English and were translated in to local language (Amharic and Afaan Oromo) and were translated back to English. Review was made by Amharic, English,
Afaan Oromo language experts and health professionals for consistency of translation of the language. Data was collected using face to face interview methods with the parents of children. Both cases and controls were interviewed by a person working on TB clinic of respective health facility after confirming their medical diagnosis from clients' medical card. The data collectors conducted the interview after providing respondents a brief orientation on the purpose of the study and its significance.

\section{Data quality control}

Before data collection, pretest was be done in $5 \%$ of the sample size population in Robe health center which were not included in the actual sampling before the actual data collection period and necessary adjustments were made on the tool.

Three days training was given to data collectors and supervisors about the objectives of the study, data collection instruments, data collection procedures, and the ethical consideration during data collection. The investigators supervised and reviewed every questionnaire for completeness and logical consistency and corrections were made at the data collection site. Data coding, entry and cleaning was performed by the investigators.

\section{Data processing, analysis and presentation}

The data was checked for completeness and consistencies, and cleaned, coded and entered using Epi Info version 3.5.4 and was exported to statistical package for social sciences (SPSS) software version 20 for analysis. Descriptive statistics was performed to describe the study population in relation to relevant variable and findings were presented as proportions.

Multiple logistic regression model was fitted to find factors associated with pediatrics TB. The candidate variables considered were age of the child, religion, ethnicity, educational status of the mother, educational status of the father, family size, availability of separate kitchen and window, family practice of feeding children raw milk, BCG vaccination status, HIV status of the child, family history of TB, occupation of the father, occupation of the mother and family size. BCG vaccination status of the children was assessed based on the presence of scar the right upper arm. In addition, the national average individual size per household was used to classify family size.

Firstly all variables were screened by carrying-out univariable analyses using a liberal $p$-value of 0.20 . All variables significant at the $20 \%$ level were included in the multivariable analysis control confounders and identify independent effect of different factors for occurrence of TB. Afterwards, stepwise logistic regression model was used to remove variables not significant at $5 \%$ significance level. The goodness of fit test was investigated 
using Hosmer and Lemeshow good-ness of fit test. All analyses were done using SPSS version 20 .

\section{Result}

A total of 432 children from 20 health facilities were selected to participate in the study, of which 426 participated in the study which gives $98.6 \%$ response rate.

\section{Socio-demographic characteristics}

Among the total 426 participants 142 were cases and 244 were controls. There were equal number of male and female 71 (50\%) among cases and controls. Among the controls, 136 (47.9\%) and 148 (52.1\%) were males and females, respectively. The mean (standard deviation) of age among cases was $8.4( \pm 4.3)$ and it was $7.3( \pm 4.1)$ among controls.

With regard to occupational status of the mother among cases, 70 (49.3\%) were housewives and 8 (5.6\%) were government employees, while among controls 107 (37.7\%) were housewives and 47 (16.5) were government employed (Table 1).

\section{Environmental and house hold factors}

From a total of 426 participants 123 (86.6\%) of cases and 226 (79.4\%) controls have privately owned house. Around 41 (28.9\%) and 39 (13.7\%) of cases and controls, respectively, has had more than six family members. According to this study, the availability and functionality of windows among cases and controls were 120 (84.5\%) among which 109 (90.8\%) were functional and 266 (93.7) among which 257 (96.6\%) were functional respectively. With regard to availability of separate kitchen for cooking, 108 (76.1\%) of cases and 253 (89.1\%) of controls have separate kitchen for cooking.

Among a total of 142 cases, majority 105 (73.9\%) of them have a habit of feeding raw milk to their child whereas only $86(30.3 \%)$ of controls have a habit of feeding raw milk to their children.

\section{Clinical characteristics of TB and co-morbid illness}

Of the total study participants, $12(8.5 \%)$ of cases had previous history of TB whereas only $6(2.1 \%)$ of controls had previous history of TB.

When asked about recent family history of $\mathrm{TB}$, while $45(31.7 \%)$ of the cases responded positively only 10 (3.5\%) said they have had family history of TB. More than a quarter $39(27.5 \%)$ of the cases and $7(2.5 \%)$ of the controls were not vaccinated for BCG.

Co-morbid illnesses that are related with pediatric $\mathrm{TB}$ were also assessed. Our study revealed that none of the cases were diabetic whereas $5(1.8 \%)$ of the controls had history of raised blood glucose level (BGL). Regarding HIV status of the study participants, 16 (11.3\%) of the cases and $4(1.4 \%)$ of the controls were infected with HIV (Table 2).

\section{Factors associated with pediatrics TB}

For the multivariable logistic regression, the variables that were found to be significant in the univariable analysis were considered. Sex of the child, family size, number of rooms in the house, availability of latrine, consumption of raw meat, previous history of TB, recent history of diarrhea and hospitalization, and presence chronic disease were found not to be statistically significant. Age of the child, mother's educational status, number of people residing in the house, availability of windows and separate kitchen, presence of waste disposal, presence of animals living in the house, consumption of raw milk, BCG vaccination status and family history of TB were found to be statistically associated with pediatrics TB. The results of the logistic regression are presented in Table 2. Higher odds of pediatrics TB was associated with age group 11-15 compared children less than or equal to 5 years (odds ratio (OR) 1.94 95\% C.I. 1.02-3.77).

Another important variable that shows strong association was family history of TB. The odds of TB among those who had recent family TB history was 10 times higher among those who didn't have family history of TB with AOR 9.84 95\% C.I. (4.22-22.92).

Higher odds of pediatrics TB was also associated with child being infected with HIV compared to those who were uninfected (AOR $=13.6$, 95\% C.I: 3.45-53.69); those children who were fed raw milk compared to those who were not $(\mathrm{AOR}=5.46$, C.I: $1.82-16.32)$. Higher odds of TB were also associated with being vaccinated for BCG vaccine compared with absence of BCG vaccination $(\mathrm{AOR}=5.46,95 \%$ C.I: $1.82-16.32)$.

\section{Discussion}

This case control study assesses predictors for the occurrence of TB among children in public health facilities. Age of the child, contact history with TB patient, absence of BCG vaccination, presence HIV infection and consumption of raw cow milk were independently associated with increased risk of pediatrics TB.

Despite previous perceptions that TB in pediatrics age do not pose greater risk, since children tend to acquire mild disease, contribute less to transmission to other people and do not impact epidemic control, pediatrics TB has been considered as an important public health problem which is easily preventable cause of disease and death.

Our study identified several risk factors that contribute to the development of pediatrics TB. Some of these factors have also been previously described [23, 24, 25, 26], and confirmed by our study. Studies indicated that various factors contribute to the development of pediatrics TB. The findings of our study indicated that the age of the child was one of the predictor for pediatric $T B$, in which the risk was higher among 11-15 age group 
Table 1 Socio demographic characteristics of pediatric patient with TB and Without TB in public health facilities of Bale zone, south east Ethiopia, 2016

\begin{tabular}{|c|c|c|c|}
\hline \multirow[t]{3}{*}{ Variable } & \multirow[t]{3}{*}{ Level } & \multicolumn{2}{|l|}{ Disease status } \\
\hline & & Case & Control \\
\hline & & Frequency (\%) & Frequency (\%) \\
\hline \multirow[t]{3}{*}{ Age } & $\leq 5$ & $39(27.5)$ & $106(37.3)$ \\
\hline & $5-10$ & $50(35.2)$ & $105(36.9)$ \\
\hline & $10-15$ & $53(37.3)$ & $73(25.7)$ \\
\hline \multirow[t]{2}{*}{ Sex } & Male & $71(50)$ & $136(47.9)$ \\
\hline & Female & $71(50)$ & $148(52.1)$ \\
\hline \multirow[t]{5}{*}{ Religion } & Muslim & $102(71.8)$ & $142(50)$ \\
\hline & Orthodox & $32(22.5)$ & $109(38.4)$ \\
\hline & Protestant & $2(1.4)$ & $30(10.6)$ \\
\hline & Catholic & $2(1.4 \%)$ & $2(0.7)$ \\
\hline & Wakefeta & $4(2.8 \%)$ & $1(0.4)$ \\
\hline \multirow[t]{5}{*}{ Ethnicity } & Amhara & $9(6.3 \%)$ & $62(21.8)$ \\
\hline & Oromo & $121(85.2 \%)$ & $178(62.7)$ \\
\hline & Tigre & $2(1.4 \%)$ & $13(4.6)$ \\
\hline & Gurage & $2(1.4 \%)$ & $14(4.9)$ \\
\hline & Others & $8(5.6 \%)$ & $17(6.0)$ \\
\hline \multirow[t]{4}{*}{ Child's educational status } & Can't read and write & $13(9.2 \%)$ & $5(1.8)$ \\
\hline & Not enrolled & $54(38.0 \%)$ & $135(47.5)$ \\
\hline & Primary school & 68 (47.9\%) & $140(49.3)$ \\
\hline & Secondary school & $7(4.9 \%)$ & $4(1.4)$ \\
\hline \multirow[t]{5}{*}{ Mother's educational status } & Can't read and write & $69(48.6 \%)$ & $59(20.8)$ \\
\hline & Can read and write & $29(20.4 \%)$ & $46(16.2)$ \\
\hline & Primary school & $20(14.1 \%)$ & $71(25.0)$ \\
\hline & Secondary education & $19(13.4)$ & $74(26.1)$ \\
\hline & Above secondary education & $5(3.5)$ & $34(12.0)$ \\
\hline \multirow[t]{5}{*}{ Father's educational status } & Can't read and write & $39(27.5)$ & $35(12.3)$ \\
\hline & Can read and write & $45(31.7)$ & $46(16.2)$ \\
\hline & Primary school & $26(18.3)$ & $48(16.9)$ \\
\hline & Secondary education & $20(14.1)$ & $86(30.3)$ \\
\hline & Above secondary education & $12(8.5)$ & $69(24.3)$ \\
\hline \multirow[t]{6}{*}{ Mother's occupation } & Farmer & $34(23.9)$ & $27(9.5)$ \\
\hline & Merchant & $25(17.6)$ & $83(29.5)$ \\
\hline & Gov't employee & $8(5.6)$ & $47(16.5)$ \\
\hline & Non gov't employee & $2(1.4)$ & $15(5.3)$ \\
\hline & Day labor & $3(2.1)$ & $5(1.8)$ \\
\hline & Housewife & $70(49.3)$ & $107(37.7)$ \\
\hline \multirow[t]{6}{*}{ Father's occupation } & Farmer & $82(57.7)$ & $73(25.7)$ \\
\hline & Merchant & $32(22.5)$ & $77(27.1)$ \\
\hline & Gov't employee & $13(9.2)$ & $84(29.6)$ \\
\hline & Non gov't employee & $6(4.2)$ & $28(9.9)$ \\
\hline & Day labor & $3(2.1)$ & $13(4.6)$ \\
\hline & Pastoral & $2(1.4)$ & $3(1.1)$ \\
\hline
\end{tabular}


Table 1 Socio demographic characteristics of pediatric patient with TB and Without TB in public health facilities of Bale zone, south east Ethiopia, 2016 (Continued)

\begin{tabular}{|c|c|c|c|}
\hline \multirow[t]{3}{*}{ Variable } & \multirow[t]{3}{*}{ Level } & \multicolumn{2}{|l|}{ Disease status } \\
\hline & & Case & Control \\
\hline & & Frequency (\%) & Frequency (\%) \\
\hline & Others & $4(2.8)$ & $6(2.1)$ \\
\hline \multirow[t]{2}{*}{ Family size } & $\leq 5$ & $65(45.8)$ & $185(65.1)$ \\
\hline & $>5$ & 77 (54.2) & 99 (34.9) \\
\hline
\end{tabular}

children when compared with children of age group $\leq 5$. This finding was supported by Federal Ministry of Health 16th National Annual review Report on Tuberculosis, proportion of TB patients among older children aged 5-14 were higher than those aged 0-4 years [27]. This could be explained by the fact that as the age of the child increase, the probability of the child to spend time outside his/her home is high which in-turn increases their chance of contact with infectious cases.

Effective investigation of TB contacts is of great importance in that they contribute greatly to early detection of active $\mathrm{TB}$, thus decreasing its severity and transmission to others. Our study unsurprisingly revealed that TB disease has a ten-fold increase among study participants with contact history with TB patients. This finding was confirmed by several previous studies conducted elsewhere [23, 28, 29, $30]$, where they indicated contact history as an important risk factor for the transmission of childhood TB. In most low- and middle-income settings, even-though investigation of $\mathrm{TB}$ contact is included in the national TB control program, it is rarely and consistently conducted due to resource constraints. However, contact history investigation merits serious consideration as a means to improve early case detection and prevent transmission of mycobacterium tuberculosis infection.

In our study, family history of feeding children raw cow milk was strongly associated with pediatric TB where children who has history of consuming raw milk had 4 folds increase in the odds of developing TB than those who don't, where previous study in Russia [24] indicated similar finding. The association between consumption of raw milk and TB in this study can be explained the fact that TB can also be caused by mycobacterium bovis which is found in unpasteurized milk. The consumption of unpasteurized milk in the study area is high. If the association proves to be due to mycobacterium bovis, which the current study has not identified, ensuring milk safety would be a public health priority.

In high HIV prevalence settings, tuberculosis (TB) and HIV/AIDS cannot be considered in isolation from each other. Co-infection with HIV, especially in sub-Saharan countries, has significantly increased the number of individuals with TB. TB is the leading cause of death in HIV positive people, and HIV infection is a significant risk factor for TB [31]. Our study found that HIV infected children are more likely to be infected with TB.

Similarly, Investigators from a case control study conducted in Zambia [32], a study in Northwest Ethiopia [17] and another study from South Africa [33] reported that TB was associated with the increased HIV infection. The current study also revealed that children who were vaccinated for BCG have a reduced risk of TB. This was evidenced by meta-analysis of available studies where $\mathrm{BCG}$ vaccine can reduce risk of TB infection by as much as $50 \%$ [26].

\section{Strengths}

We used case control study design which is appropriate to address the research question. The cases and controls were also taken from the same institutions which made it easy to identify controls.

\section{Limitations}

One of the limitations of this study might be recall bias as study participants may not remember condition of the past. Additional limitation was environmental and house hold factors were assessed without observation and this may have underestimated or overestimated the effect in the findings. Although malnutrition is important factor that highly contribute for the occurrence of $\mathrm{TB}$ in children, we were unable to analyze it due to incompleteness of most of the data.

\section{Conclusion}

The finding of this study has given insight on different predictors of pediatric TB. Children that have contact history with adult individual with $\mathrm{TB}$ are at risk of acquiring the infection. BCG vaccination status, HIV status, age of the child and family practice of feeding children raw milk are the independent predicators of pediatric TB. Therefore Bale Zonal health office is highly recommended to work with different stakeholders to increase public awareness on risk factors of pediatric $\mathrm{TB}$ and its transmission. Contact 
Table 2 Logistic regression analysis of factors associated with pediatric TB in public health facilities of Bale Zone, south east Ethiopia, 2016

\begin{tabular}{|c|c|c|c|c|c|}
\hline \multirow[t]{3}{*}{ Variable } & \multirow[t]{3}{*}{ Level } & \multicolumn{2}{|l|}{ Disease status } & \multirow[t]{3}{*}{ COR $(95 \% \mathrm{Cl})$} & \multirow[t]{3}{*}{ AOR $(95 \% \mathrm{Cl})$} \\
\hline & & Control & Case & & \\
\hline & & Frequency (\%) & Frequency (\%) & & \\
\hline \multirow[t]{2}{*}{ Sex } & Male & $136(47.9)$ & $71(50.0)$ & 1 & \\
\hline & Female & $148(52.1)$ & $71(50.0)$ & $1.08(0.72-1.63)$ & - \\
\hline \multirow[t]{3}{*}{ Age } & $\leq 5$ & $106(37.3)$ & $39(27.5)$ & 1 & 1 \\
\hline & $6-10$ & $105(37.5)$ & $50(35.2)$ & $1.29(0.78-3.18)$ & $1.26(0.67-2.43)$ \\
\hline & $11-15$ & $73(25.7)$ & $53(37.3)$ & $1.97(1.18-3.18)$ & $1.94(1.02-3.77)$ \\
\hline \multirow[t]{5}{*}{ Mother's educational status } & Can't read and write & $59(20.8)$ & $69(48.6)$ & $7.95(2.92-21.64)$ & $2.35(0.68-5.05)$ \\
\hline & Can read and write & $46(16.2)$ & $29(20.4)$ & $4.28(1.50-12.22)$ & $1.54(0.43-5.49)$ \\
\hline & Primary & $71(25.0)$ & $20(14.1)$ & $1.91(0.66-5.53)$ & $1.68(0.49-5.72)$ \\
\hline & Secondary & $74(26.1)$ & $19(13.4)$ & $1.76(0.60-5.06)$ & $1.14(0.62-2.17)$ \\
\hline & Tertiary & $34(12.0)$ & $5(3.5)$ & 1 & \\
\hline \multirow[t]{2}{*}{ Family size } & $\leq 5$ & $185(65.1)$ & $65(45.8)$ & 1 & \\
\hline & $>5$ & 99 (34.9) & $77(54.2)$ & $2.21(0.46-3.33)$ & - \\
\hline \multirow[t]{3}{*}{ No of people living in the house } & $\leq 3$ & $44(15.5)$ & $13(9.2)$ & 1 & \\
\hline & $4-6$ & $201(70.8)$ & $88(62.0)$ & $1.48(0.76-2.88)$ & $1.55(0.63-3.81)$ \\
\hline & $>6$ & $39(13.7)$ & $41(28.9)$ & $3.56(1.66-7.56)$ & $1.75(0.55-5.57)$ \\
\hline \multirow[t]{2}{*}{ Number of rooms in the house } & $1-3$ & $254(89.4)$ & $136(95.8)$ & 1 & \\
\hline & $4-6$ & $30(10.6)$ & $6(4.2)$ & $0.37(0.15-1.92)$ & - \\
\hline \multirow[t]{2}{*}{ Availability of windows } & Yes & $266(93.7)$ & $120(84.5)$ & 1 & \\
\hline & No & $18(6.3)$ & $22(15.5)$ & $2.7(1.40-5.32)$ & $0.85(0.33-2.16)$ \\
\hline \multirow[t]{2}{*}{ Availability of separate kitchen } & Yes & $253(89.1)$ & $108(76.1)$ & 1 & \\
\hline & No & $31(10.9)$ & $34(23.9)$ & $2.56(1.50-4.39)$ & $0.53(0.20-1.22)$ \\
\hline \multirow[t]{2}{*}{ Availability of latrine } & Yes & $252(88.7)$ & $113(79.6)$ & 1 & \\
\hline & No & $32(11.3)$ & $29(20.4)$ & $2.02(0.99-3.50)$ & - \\
\hline \multirow[t]{2}{*}{ Waste disposal } & In the compound & $97(34.2)$ & $78(54.9)$ & $2.35(1.56-3.55)$ & $1.03(0.59-1.81)$ \\
\hline & Outside compound & $187(65.8)$ & $64(45.1)$ & 1 & \\
\hline \multirow[t]{2}{*}{ Availability of tap water } & Yes & $186(65.5)$ & $50(35.2)$ & 1 & \\
\hline & No & $98(34.5)$ & $92(64.8)$ & $3.49(2.29-5.33)$ & $1.27(0.66-2.44)$ \\
\hline \multirow[t]{2}{*}{ Do animal live in your house } & Yes & $34(12.0)$ & $54(38.0)$ & $4.51(2.76-7.39)$ & $1.75(0.86-3.56)$ \\
\hline & No & $250(88.0)$ & $88(62.0)$ & 1 & \\
\hline \multirow[t]{2}{*}{ Do you feed your child row meat } & Yes & $204(71.8)$ & $115(81.0)$ & $1.67(1.01-2.73)$ & - \\
\hline & No & $80(28.2)$ & $27(19.0)$ & 1 & \\
\hline \multirow[t]{2}{*}{ Do you feed your child raw milk } & Yes & $86(30.3)$ & $105(73.9)$ & $6.53(4.16-10.27)$ & $4.23(2.26-7.88)$ \\
\hline & No & $196(69.7)$ & $37(26.1)$ & 1 & \\
\hline \multirow[t]{2}{*}{ Previous history of TB } & Yes & $6(2.1)$ & $12(8.5)$ & $4.27(0.96-11.65)$ & - \\
\hline & No & $278(97.9)$ & $130(91.5)$ & 1 & \\
\hline \multirow[t]{2}{*}{ BCG vaccination status } & Yes & $277(97.5)$ & $103(72.5)$ & 1 & \\
\hline & No & $7(2.5)$ & $39(27.5)$ & $13.52(6.13-29.88)$ & $5.46(1.82-16.32)$ \\
\hline \multirow[t]{2}{*}{ Family history of TB } & Yes & $10(3.5)$ & $45(31.7)$ & $12.71(6.17-26.20)$ & $9.84(4.22-22.92)$ \\
\hline & No & $274(96.5)$ & $97(68.3)$ & 1 & \\
\hline Vaccination at 9 month & Yes & $254(89.4)$ & $87(61.3)$ & 1 & \\
\hline
\end{tabular}


Table 2 Logistic regression analysis of factors associated with pediatric TB in public health facilities of Bale Zone, south east Ethiopia, 2016 (Continued)

\begin{tabular}{|c|c|c|c|c|c|}
\hline \multirow[t]{3}{*}{ Variable } & \multirow[t]{3}{*}{ Level } & \multicolumn{2}{|l|}{ Disease status } & \multirow[t]{3}{*}{ COR $(95 \% \mathrm{Cl})$} & \multirow[t]{3}{*}{ AOR $(95 \% \mathrm{Cl})$} \\
\hline & & Control & Case & & \\
\hline & & Frequency (\%) & Frequency (\%) & & \\
\hline & No & $30(10.6)$ & $55(38.7)$ & $5.35(3.22-8.89)$ & $0.98(0.44-2.19)$ \\
\hline \multirow[t]{2}{*}{ Resent history of diarrheal disease } & Yes & $51(18.0)$ & $16(11.3)$ & $0.58(0.32-1.06)$ & - \\
\hline & No & $233(82.0)$ & $126(88.7)$ & 1 & \\
\hline \multirow[t]{2}{*}{ Resent history of hospitalization } & Yes & $37(13.0)$ & $31(21.8)$ & $1.86(1.01-3.16)$ & - \\
\hline & No & $247(87.0)$ & $111(78.2)$ & 1 & \\
\hline \multirow[t]{2}{*}{ HIV status of the child } & Positive & $4(1.4)$ & $16(11.3)$ & $8.89(2.91-27.12)$ & $13.61(3.45-53.69)$ \\
\hline & Negative/unknown & $280(98.6)$ & $126(88.7)$ & 1 & \\
\hline \multirow[t]{2}{*}{ Does the child has any chronic disease } & Yes & $14(4.9)$ & $12(8.5)$ & $1.78(0.8-3.96)$ & - \\
\hline & No & $270(95.1)$ & $130(91.5)$ & 1 & \\
\hline
\end{tabular}

tracing and contact screening should be correctly implemented to prevent transmission of the infection and early diagnosis. Further research should be done to investigate if bovine $\mathrm{TB}$ is dominant in the area to take appropriate measure.

\section{Abbreviations \\ AIDS: Acquired immune deficiency syndrome; BZHB: Bale zone health bureau; Cl: Confidence interval; DOTS: Directly observed treatment, short course; EPI: Expanded program of immunization; EPTB: Extra-pulmonary tuberculosis; FMOH: Federal Ministry of Health; HIV: Human immunodeficiency virus; MDR-TB: Multidrug resistant tuberculosis; MWU: MaddaWalabu University; OR: Odds Ratio; PTB: Pulmonary tuberculosis; TB: Tuberculosis; TB/HIV: Tuberculosis and HIV co-infection; TBIC: Tuberculosis infection control; WHO: World Health Organization; XDR-TB: Extensively drug resistant tuberculosis}

\section{Acknowledgements}

We would like to express our deepest gratitude to MaddaWalabu University for funding this research. We would also like to extend our appreciation to the data collectors who participated in the study. We are also grateful to all hospital, health center administration and study subjects.

\section{Funding}

The study was funded by MaddaWalabu University, Ethiopia. The funder has no role in study design, data collection and analysis, interpretation of data, decision to publish, or preparation of the manuscript.

\section{Availability of data and materials}

Data is available and it can be accessed from the corresponding author when asked with reasonable inquiry.

\section{Authors' contributions}

BG conceived and designed the study, performed data analysis, compiled the whole work and prepared the manuscript. TA, TM, participated in design, analysis, reviewing the main document and took part in the critical revision of the manuscript. AAA, NW participated in analysis, reviewing the main document and took part in the critical revision of the manuscript. All authors read and approved the final manuscript.

\section{Ethics approval and consent to participate}

Ethical clearance was obtained from MaddaWalabu University (MWU) research ethical committee and support letter was taken from zonal health bureau. Permission was asked from each selected health facility principal. The ethics committee approved obtaining informed consent verbally because most of the study participants have no formal education and are unable to read and write. Each study subject's parents were asked their verbal consent by explaining objectives of the study and its significance. In addition ascent was asked from children who can speak and understand. Parents were informed that their participation in the study was voluntary and they were free to withdraw their participation at any time they want. Participant's confidentiality were maintained by omitting the respondents name and address in the questionnaire. Study respondents were given assurance that there were no physical and emotional harm resulting from participating in the study.

\section{Competing interests}

The authors declare that they have no competing interests.

\section{Publisher's Note}

Springer Nature remains neutral with regard to jurisdictional claims in published maps and institutional affiliations.

\section{Author details}

${ }^{1}$ College of Medicine and Health Sciences, Allied School of Health Science, Addis Ababa University, Addis Ababa, Ethiopia. ${ }^{2}$ Department of Occupational Health, Higher Education Relevance and Quality Agency, Addis Ababa, Ethiopia. ${ }^{3}$ Ethiopian Public Health Institute, Food Science and Nutrition Directorate, Addis Ababa, Ethiopia. ${ }^{4}$ College of Health and Medical Sciences, School of public health, Haramaya University, Harar, Ethiopia. ${ }^{5}$ Addis Ababa, Ethiopia. ${ }^{6}$ Harar, Ethiopia.

Received: 14 December 2017 Accepted: 24 May 2018

Published online: 04 June 2018

\section{References}

1. World Health Organization Fact Sheet No.104: Tuberculosis. Geneva: WHO; 2010. Available from: http://www.who.int/mediacentre/factsheets/fs104/en/ print.html.

2. Fauci B, Kasperetal H. Principle of Internal Medicine. United States of America: McGraw-Hill Medical Publishing Devision; 2008. 17 $7^{\text {th }}$ edition, chapter 38.

3. WHO. Global tuberculosis report. Geneva: WHO; 2015. www.who.int/tb/data

4. WHO. Global tuberculosis report. 2014.http://www.who.int/tb/publications/ global_report/en/

5. FMOH. Ethiopian Population Based National TB Prevalence Survey Research Protocol. Addis Ababa: FMOH; 2010.

6. WHO. Global tuberculosis report. Library cataloguing-in-publication data. 2014.

7. Dodd PJ, et al. The global burden of tuberculosis mortality in children: a mathematical modeling study. Lancet Glob Health. 2017;5(9):e898-906.

8. WHO. Global tuberculosis report 2016. Geneva: World health organization; 2016.

9. Tsai K, Chang H, et al. Childhood tuberculosis: epidemiology, diagnosis, treatment and vaccination. Pediatr Neonatol. 2013;54(5):295-302. 
10. Jamie C, Jessica G. Assessing Tuberculosis Management and Prevention in Rural and Semi-urban Ethiopia. USA: University of Washington; 2009.

11. Bale Zone Health Bureau. Annual report. Bale Robe: Bale Zone Health Bureau; 2015

12. Anamarija J, et al. Risk factors for pulmonary tuberculosis in Croatia: a matched case control study. BMC Public Health. 2013;13:991.

13. Kirenga BJ, et al. Tuberculosis risk factors among tuberculosis patients in Kampala, Uganda: implications for tuberculosis control. BMC Public Health. 2015;15:13. https://doi.org/10.1186/s12889-015-1376-3.

14. Mohamed R, Mohamed A, et al. Risk factors of childhood tuberculosis in rural Bangladesh. WHO South-East Asia J Public Health. 2012;1(1):76-84.

15. Kefyalew T. Risk Factors for Active Tuberculosis in Children in Contact with Smear Positive Cases in Southern Ethiopia: Maters Thesis University of Liverpool; 2010. p. 57-9. http://www.academia.edu/2492196/.

16. Cheru T, Takele T, et al. Environmental and host-related determinants of tuberculosis in Metema district, north-West Ethiopia. Drug Healthcare Patient Saf. 2015;7:87-95.

17. Moges B, et al. Prevalence of smear positive pulmonary tuberculosis among prisoners in North Gondar zone prison, Northwest Ethiopia. BMC Infect Dis. 2012;12:352. https://doi.org/10.1186/1471-2334-12-352

18. Muñoz-Sellart M, et al. Treatment outcome in children with tuberculosis in southern Ethiopia. Scand J Infect Dis. 2009:41:4505.

19. Ramos A, et al. Childhood and adult tuberculosis in a rural hospital in Southeast Ethiopia: a ten-year retrospective study. BMC Public Health. 2010;10:215.

20. FMOH. Ethiopia National comprehensive Tuberculosis, Leprosy, TB/HIV diagnosis and treatment manual. Addis Ababa: FMOH; 2016.

21. Marais B, et al. The natural history of childhood intra thoracic tuberculosis, a critical review of the pre-chemotherapy literature. Cold Spring HarbPerspect Med. 2014;4:a017855.

22. FMOH. Ethiopian National Population Based Tuberculosis Prevalence Survey. Addis Ababa: FMOH; 2011

23. Karim $\mathrm{M}$, et al. What cannot be measured cannot be done; risk factors for childhoodtuberculosis: a case control study. Bangladesh Med Res Counc Bull. 2012;38:27-32.

24. Coker R, et al. Risk factors for pulmonary tuberculosis in Russia: case-control study. BMJ. 2006:332:85-7.

25. Singh $M$, et al. Prevalence and risk factors for transmission of infection among children in household contact with adults having pulmonary tuberculosis. Arch Dis Child. 2005;90:624-8.

26. Colditz GA, et al. Efficacy of BCG vaccine in the prevention of tuberculosis meta-analysis of the published literature. JAMA. 1994;271(9):698-702. https://doi.org/10.1001/jama.1994.03510330076038.

27. $\mathrm{FMOH}$. Evaluating the National TB Control Program: Challenges and ways forward Disease Prevention and Control. 16th National Annual Review Meeting Group Discussion. Ethiopia: FMOH; 2014.

28. Simon S, Ben JM, et al. Culture-confirmed childhood tuberculosis in cape town, South Africa: a review of 596 cases. BMC Infect Dis. 2007:7:140.

29. Jurcev-Savicevic A, et al. Risk factors for pulmonary tuberculosis in Croatia: a matched case- control study. BMC Public Health. 2013;13:991.

30. Morrison J, Pai M, Hopewell PC. Tuberculosis and latent tuberculosis infection in close contacts of people with pulmonary tuberculosis in lowincome and middle-income countries: a systematic review and metaanalysis. Lancet Infect Dis. 2008;8(6):359-68.

31. Ashley K. TB, HIV, and TB/HIV co-infection: community knowledge and stigma in western Uganda by maters thesis 2012.

32. Boccia D, Hargreaves J, De Stavola BL, Fielding K, Schaap A, GodfreyFaussett P, et al. (2011) The association between household socioeconomic position and prevalent tuberculosis in Zambia: a case-control study. PLoS One 6(6): e20824. https://doi.org/10.1371/journal.pone.0020824

33. Hesseling $A C$, et al. High incidence of tuberculosis among HIV-infected infants: evidence from a south African population-based study highlights the need for improved tuberculosis control strategies. Clin Infect Dis. 2009:48:108-14.

\section{Ready to submit your research? Choose BMC and benefit from:}

- fast, convenient online submission

- thorough peer review by experienced researchers in your field

- rapid publication on acceptance

- support for research data, including large and complex data types

- gold Open Access which fosters wider collaboration and increased citations

- maximum visibility for your research: over $100 \mathrm{M}$ website views per year

At BMC, research is always in progress.

Learn more biomedcentral.com/submissions 